\title{
Hepatocellular carcinoma-associated protein markers investigated by MALDI-TOF MS
}

\author{
XIAO-LI CHEN ${ }^{1}$, LE ZHOU ${ }^{2}$, JUN YANG ${ }^{1}$, FU-KUN SHEN ${ }^{1}$, SHI-PING ZHAO ${ }^{1}$ and YI-LI WANG ${ }^{1,3}$ \\ Departments of ${ }^{1}$ Pathology, and ${ }^{2}$ Neurosurgery, the Second Affiliated Hospital, School of Medicine, \\ Xi'an Jiaotong University, Shaanxi 710004; ${ }^{3}$ Key Laboratory of Biomedical Information Engineering of National \\ Administration of Education, Institute for Cancer Research, Xi'an Jiaotong University, Shaanxi 710061, P.R. China
}

Received February 24, 2010; Accepted May 21, 2010

DOI: $10.3892 / \mathrm{mmr} 00000302$

\begin{abstract}
Hepatocellular carcinoma (HCC) is one of the most common types of cancer worldwide. The initial hepatocellular alterations that precede the appearence of HCC include chronic viral hepatitis/cirrhosis, foci of phenotypically altered hepatocytes and, subsequently, dysplastic hepatocytes that form foci and nodules. These changes cause a discrepancy in the microenvironment of liver cells, which may result in changes in the protein expression profile of the cells. The aim of the present study was to investigate differences between the protein expression profiles at various stages of liver disease in order to better understand the mechanisms of HCC and to identify potential biomarkers for its early diagnosis. The proteins of specific cells were obtained from HCC tissue sections and pre-cancerous lesions using a manual microdissection technique, and were investigated by a two dimensional gel electrophoresis (2-DE) MALDI-TOF MS proteomics approach. Select identified proteins were reconfirmed by immunohistochemistry. A total of 95 differentially expressed proteins, with an over 2-fold disparity in expression levels between cells of varying morphology during the stages of hepatocarcinogenesis, were detected by 2-DE. Among these 95 proteins, 80 were determined to be involved in numerous cell functions, including cell growth and proliferation, protein synthesis and metabolism, apoptosis and signal transduction. These identified proteins, which include stratifin (14-3-3), transgelin 2, heat-shock protein (HSP)70, HSP27, manganese superoxide dismutase, prohibitin, DJ1, $\alpha$-enolase, peroxiredoxin 6 , aldo-keto reductase family member B10, phosphoglycerate kinase $1, \alpha-1$-antitrypsin and nm23-H1, may play a role in the development of HCC. Protein expression profiles differed markedly between the HCC tissue samples
\end{abstract}

Correspondence to: Professor Yi-Li Wang and Dr Xiao-Li Chen, Department of Pathology, the Second Affiliated Hospital, School of Medicine, Xi'an Jiaotong University, X'ian, 710004 Shaanxi, P.R. China

E-mail: wangyili@mail.xjtu.edu.cn; chx164@yahoo.com.cn

Key words: hepatocellular carcinoma, pre-cancerous lesion, microdissection, proteomics and pre-cancerous lesions, suggesting that alterations in protein expression occurred frequently during the process of hepatocarcinogenesis. Analysis of the differential expression of proteins related to the development of HCC may help elucidate the molecular mechanisms of the disease. These proteins may also serve as candidate biomarkers for early HCC diagnosis.

\section{Introduction}

Hepatocellular carcinoma (HCC) is one of the world's most common malignancies. The majority of HCC cases are associated with chronic hepatitis or cirrhosis. Pathological changes in HCC are involved in liver cell degeneration and necrosis, inflammatory cell infiltration, hepatocyte regeneration and fibrous tissue proliferation. During the development of $\mathrm{HCC}$, the liver undergoes a series of morphological changes, including chronic viral hepatitis/cirrhosis, foci of phenotypically altered hepatocytes and atypical hyperplasia (1-4). These changes result in an altered microenvironment, in which the intracellular protein expression pattern is changed as well.

The proteomics approach allows for the analysis of changes in the protein expression profile of cells during disease progression. By comprehensively analyzing changes in protein expression patterns over the course of disease progression, valuable information may be generated for the early diagnosis and treatment of liver cancer. Using a combination of proteomics techniques, classic morphological pathology and microdissection, we analyzed the protein expression profile of hepatocarcinogenesis at various stages of liver disease (including chronic viral hepatitis, cirrhosis, foci of altered hepatocytes and atypical hyperplasia) and in different histological types of liver cancer. The aim of this study was to elucidate the molecular mechanisms of liver cancer, and to identify valuable candidate biomarkers for the early diagnosis of the disease.

\section{Materials and methods}

Reagents and instruments. Immobilized $\mathrm{pH}$ gradient dry strips (IPG strip, pH 3-10NL, 13 cm), IPG buffer (pH 3-10NL), covering liquid, a silver staining kit, IPGphor isoelectric focusing instrument, SE600 vertical electrophoresis tank, electrophoresis device and Image Master 5.0 image analysis 
software were purchased from Amersham Biosciences Inc. (Sweden). Centrifugal dryers and an ABI Voyager DE MALDI-TOF mass spectrometer were from Applied Biosystems (USA). Dithiothreitol (DTT), iodoacetamide (IAA), sequencing grade TPCK Trypsin (TPCK-trypsin), trifluoroacetic acid (TFA), matrix $\alpha$-cyano-4-hydroxy-cinnamic acid (CHCA), TBP, OBG and MEGA-10 were purchased from Sigma. Silver nitrate, acrylamide, methylene bis-acrylamide, urea, thiourea, glycine, Tris, CHAPS and SDS were from Promega (USA). All solutions were prepared with MilliQ water.

Microdissection and sample preparation. Fresh specimens from HCC surgical resections were collected and the nonnecrotic area was pathologically confirmed. Frozen sections $(5 \mu \mathrm{m})$ of $\mathrm{HCC}$ and adjacent cirrhosis samples were processed separately. The cancer cells and the altered hepatocytes were identified by routine H\&E staining observed under an optical microscope, carefully marked with the syringe needle at a low magnification, and excised. The remaining 10 to $15-\mu \mathrm{m}$ thick continuous frozen sections with no staining were neatly stacked under the slice of H\&E stained tissue (ice operation) using a scalpel to obtain the corresponding parts of the tissue, and then collected into a $1.5-\mathrm{ml}$ Eppendorff tube with lysis buffer. The tissue cells were lyzed in a cocktail of $9 \mathrm{~mol} / \mathrm{l}$ urea, $40 \mathrm{~g} / \mathrm{l} \mathrm{CHAPS}, 40 \mathrm{mmol} / \mathrm{l}$ Tris and $40 \mathrm{mmol} / \mathrm{l} \mathrm{DTT}$ and centrifuged at $40,000 \mathrm{x} \mathrm{g}$ for $1 \mathrm{~h}$ at $4^{\circ} \mathrm{C}$. Protein concentrations were determined by the Bradford method. All samples were stored in aliquots at $-80^{\circ} \mathrm{C}$ before analysis.

Two-dimensional electrophoresis. Two-dimensional electrophoresis (2-DE) was manually performed according to the manufacturer's instructions with minor modifications. Firstdimension isoelectric focusing (IEF) is an electrophoretic method that separates proteins according to their isoelectric points (pI). IEF was carried out on an IPGphor system (Amersham Biosciences Inc.) using 13-cm strips (pH 3-10, non-linear) and $80 \mu \mathrm{g}$ of protein in a $250 \mu \mathrm{l}$ sample solution. Rehydration and isoelectric focusing were automatically performed at $20^{\circ} \mathrm{C}$ and $60 \mu \mathrm{A}$ per strip as follows: $30 \mathrm{~V}, 6 \mathrm{~h}$; $60 \mathrm{~V}, 6$ h; $200 \mathrm{~V}, 2$ h; $500 \mathrm{~V}, 2$ h; 1,000 V, 1 h; 8,000 V, 3 h. After IEF, the focused strips were equilibrated in balanced solution I (6 mol/l urea, 30\% glycerol, $2 \%$ SDS and 1\% DTT) and balanced solution II (6 mol/1 urea, 30\% glycerol, $2 \%$ SDS and $2.5 \%$ IAA) for $15 \mathrm{~min}$, respectively, with gentle agitation. Second dimensional separation was performed on $12.5 \%$ SDS-PAGE at a 30-mA constant current per gel using Hoefer SE600 vertical gel electrophoresis chambers. The proteins were separated according to molecular weight.

Silver nitrate staining. 2-DE gels were stained with silver nitrate according to the kit instructions. The basic processes were as follows: the gels were fixed in $40 \%$ methanol and $10 \%$ acetic acid for $1 \mathrm{~h}$ or overnight, sensitized in $30 \%$ methanol, $0.2 \% \mathrm{Na}_{2} \mathrm{~S}_{2} \mathrm{O}_{3}$ and $6.8 \%$ anhydrous sodium acetate for $30 \mathrm{~min}$, and stained with $0.25 \%$ silver nitrate for $20 \mathrm{~min}$. After that, the gels were developed in $2.5 \%$ sodium carbonate and $0.0074 \%$ formaldehyde for 5-10 min to reveal visible clear spots, then $1.46 \%$ EDTA $\mathrm{Na}_{2} \cdot \mathrm{H}_{2} \mathrm{O}$ was added in a timely fashion to terminate the reaction. The above steps were carried out at room temperature on a shaker. The stained gels were stored in $1 \%(\mathrm{v} / \mathrm{v})$ acetic acid at $4^{\circ} \mathrm{C}$.

Gel image analysis. The stained gels were captured by transmission scanning and were analyzed with Image Master 5.0. Through spot detection, comparative and quantitative analysis, protein spots with a staining intensity increased by more than 2-fold were identified and determined to be differentially expressed. The selected protein spots were manually excised from the gels and stored at $-80^{\circ} \mathrm{C}$ until analysis.

In-gel digestion. In-gel digestion of proteins was carried out according to Zhou's method (5) with minor modifications. Briefly, the differentially expressed protein spots were de-stained with $100 \mathrm{mmol} / \mathrm{l}$ sodium thiosulfate and $30 \mathrm{mmol} / \mathrm{l}$ potassium ferricyanide (1:1), reduced with $10 \mathrm{mmol} / \mathrm{l} \mathrm{DTT}$, $25 \mathrm{mmol} / \mathrm{l}$ ammonium bicarbonate $\left(\mathrm{NH}_{4} \mathrm{HCO}_{3}\right)$ for $1 \mathrm{~h}$ at $56^{\circ} \mathrm{C}$, then incubated with $25 \mathrm{mmol} / 1 \mathrm{NH}_{4} \mathrm{HCO}_{3}$ and $55 \mathrm{mmol} / \mathrm{l}$ iodine acetamide solution in the dark for $45 \mathrm{~min}$. After drying, the protein spots were incubated with TPCK-trypsin enzyme $(0.05 \mu \mathrm{g} / \mu \mathrm{l})$ overnight at $37^{\circ} \mathrm{C}$. Tryptic digests were extracted with $50 \%$ acetonitrile (CAN) $+0.2 \%$ TFA by ultrasonic extraction for $15 \mathrm{~min}$. The polypeptide extracts were dried in a vacuum concentrator at room temperature.

MALDI-TOF MS analysis of polypeptide samples. Mass spectrometry analysis was performed using the Voyager-DE MALDI-TOF mass spectrometer, operated in the delayed extraction and linear mode. The peptide samples were combined with saturated CHCA matrix. The MALDI spectra averaged over 100 laser shots. All mass spectra were calibrated externally using a standard peptide mixture (angiotensin I, neurotensin, ACTH1-17 and ACTH18-39). Internal calibration was performed using the auto-digestion peaks of trypsin.

Database searching and identification of proteins. Mascot (http://www.matrixscience.com) and ProFound (http://prowl. rockfeller.edu) software was used to search for the peptide mass fingerprints obtained by the MALDI-TOF MS in the NCBInr, MSDB or SWISS-PROT databases. The parameters of the search were as follows: the mass of peptide fragments ranged from 800 to $5,000 \mathrm{Da}$, one missed cleavage site was allowed; the peptide molecular weight maximum allowable error was $\pm 1.0 \mathrm{Da}$, and restriction was placed on the species of Homo sapiens. The modifications allowed for the carboxyamidomethylation of cysteine and oxidation of methionine (carbamidomethyl-Cys).

Immunohistochemistry. Samples from 27 cases of liver cancer (22 males and 5 females; 26-85 years of age, mean 52.5) and 10 cases of liver cirrhosis ( 6 males and 4 females; 33-68 years of age, mean 46.7) were fixed in $10 \%$ neutral formalin, paraffin-embedded, cut into 5- $\mu \mathrm{m}$ serial sections and placed on APES-coated glass slides. The slides were incubated at $65^{\circ} \mathrm{C}$ for $24 \mathrm{~h}$, then stored at $-70^{\circ} \mathrm{C}$ until use. Immunohistochemical staining was performed with mouse anti-human Cathepsin D (Cath D) and heat-shock protein 70 (HSP70) monoclonal antibodies (Chemicon Inc.). The staining steps were as follows: sections were deparaffinized, rehydrated and rinsed in PBS for $5 \mathrm{~min}$. Antigen retrieval was carried out in $5-\mathrm{mM}$ 

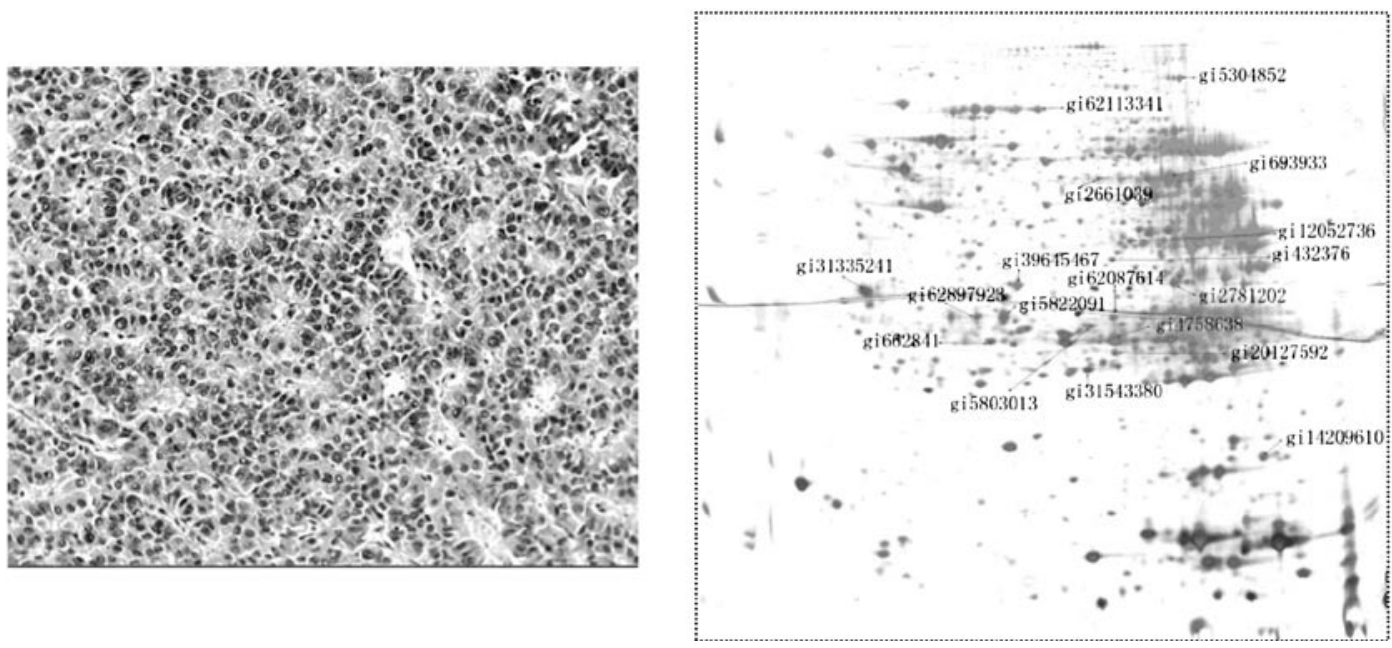

Figure 1. Morphology and silver-stained 2-DE pattern in a representative HCC sample obtained by microdissection. Proteins were separated on pH 3-10 nonlinear IPG strips and then by $12.5 \%$ SDS-PAGE. Proteins were identified using MALDI-TOF mass spectrometry. The GI numbers on the maps are accession numbers from the NCBInr database.
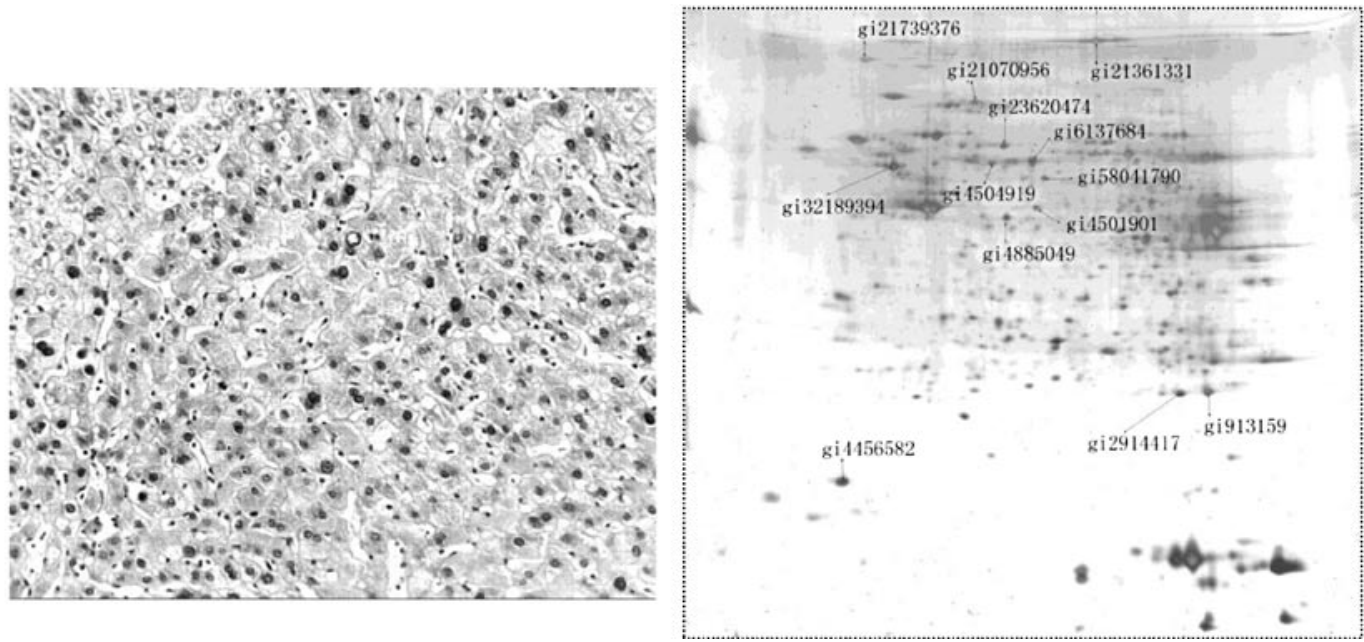

Figure 2. Morphology and 2-DE protein expression pattern of nodules of altered hepatocytes (NAH) from frozen histological sections obtained by microdissection. The GI numbers on the maps are accession numbers from the NCBInr database and represent the proteins of interest and differential protein spots compared to HCC.

citrate buffer. After inactivation of endogenous peroxidase with $5 \% \mathrm{H}_{2} \mathrm{O}_{2}$ for $30 \mathrm{~min}$ at room temperature, the sections were blocked with rabbit serum for $30 \mathrm{~min}$ at $37^{\circ} \mathrm{C}$ and then incubated with the primary antibodies diluted 1:50-100 overnight at $4^{\circ} \mathrm{C}$. The sections were incubated in biotinylated rabbit anti-mouse $\mathrm{IgG}$ for $30 \mathrm{~min}$ at $37^{\circ} \mathrm{C}$ and developed with $0.05 \% \mathrm{DAB}+0.03 \% \mathrm{H}_{2} \mathrm{O}_{2}$ for $5-10$ min. Running water was used to terminate the reaction. Finally, sections were counterstained with hematoxylin and mounted with neutral resin solution. As a negative control, PBS was used instead of primary antibody. The section known to be positive for HCC was used as the positive control.

\section{Results}

Proteomic pattern of hepatocellular carcinoma and altered hepatocytes by 2-DE. The 2-DE maps of HCC, liver cirrhosis nodules, altered hepatocytes and mixed liver cell foci were obtained using identical methodology, repeated twice in each case. The results of 2 -DE revealed that the protein expression pattern in the same case with different histological morphology was quite similar; indeed, it was possible to match the majority of protein spots with each other. However, a number of protein spots were differentially expressed, indicating that certain protein spots only appeared in the HCC tissues while others were only expressed in the liver cirrhosis altered liver cell nodules. It is also possible that the quality of protein expression differed between cases (Figs. 1 and 2).

MALDI-TOF MS analysis and identification of differential proteins. A total of 95 differentially expressed protein spots (57 HCC, 10 liver cirrhosis nodules, 13 large-cell mixed liver cell foci and 15 altered hepatocytes nodules) were identified and cut from the 2-DE gels. By MALDI-TOF MS following in-gel digestion with TPCK-trypsin, the peptide mass fingerprinting (PMF) maps of all the spots were obtained. These 
Table I. Proteins overexpressed in hepatocellular carcinoma.

\begin{tabular}{|c|c|c|c|}
\hline $\begin{array}{l}\text { NCBI/ } \\
\text { Swiss-Prot no. }\end{array}$ & $\begin{array}{l}\text { Molecular weight } \\
\qquad\left(\mathrm{x} 10^{3} / \mathrm{IP}\right)\end{array}$ & $\begin{array}{c}\text { Sequence } \\
\text { coverage }(\%)\end{array}$ & Name \\
\hline gil37789701 & $9.832 / 5.58$ & 59 & Immunoglobulin $\lambda$ light chain variable region \\
\hline gil14600245 & $16.74 / 4.96$ & 66 & TCR $\beta$ chain V $\beta 13 S 3-Y G D G N T G E L ~ J \beta 2.2$ \\
\hline gil9508585 & 29.13/4.79 & 40 & Tropomyosin isoform \\
\hline gil5453559 & $18.54 / 5.21$ & 58 & $\begin{array}{l}\text { ATP synthase, } \mathrm{H}+\text { transporting, mitochondrial F0 complex, } \\
\text { subunit } \mathrm{d} \text { isoform a }\end{array}$ \\
\hline gil15277488 & $46.94 / 6.53$ & 34 & IDH1 protein \\
\hline gil15277503 & $40.56 / 5.55$ & 36 & ACTB protein \\
\hline gil1208427 & $57.19 / 5.98$ & 44 & ER-60 protease \\
\hline gil20138951 & $84.48 / 9.8$ & 20 & PKP1_HUMAN Plakophilin 1 (Band-6-protein) (B6P) \\
\hline gil21040386 & $74.19 / 6.0$ & 35 & Heat shock 70 kDa protein 9B (mortalin-2) \\
\hline gil24234688 & $74.02 / 5.9$ & 28 & Heat shock $70 \mathrm{kDa}$ protein 9B precursor \\
\hline gil16507237 & $72.46 / 5.1$ & 33 & Heat shock $70 \mathrm{kDa}$ protein 5 (glucose-regulated protein, $78 \mathrm{kDa}$ ) \\
\hline gil7437388 & $57.28 / 6.0$ & 61 & Protein disulfide-isomerase (EC 5.3.4.1) ER60 precursor \\
\hline gil494296 & $26.51 / 5.3$ & 66 & Chain B, Cathepsin D (E.C.3.4.23.5) \\
\hline gil4505773 & $29.86 / 5.6$ & 71 & Prohibitin \\
\hline gil4504517 & $22.84 / 6.0$ & 40 & Heat shock 27 kDa protein 1 \\
\hline gil19068194 & $28.86 / 6.1$ & 41 & Hepatocarcinoma high expression protein \\
\hline gil5453559 & $18.54 / 5.2$ & 76 & ATP synthase, $\mathrm{H}+$ transporting, mitochondrial F1F0, subunit $\mathrm{d}$ \\
\hline gil438069 & $22.05 / 6.8$ & 32 & Thiol-specific antioxidant protein \\
\hline gil31543380 & $20.09 / 6.3$ & 61 & Oncogene DJ1 \\
\hline gil29468184 & $19.92 / 5.4$ & 48 & NM23-H1 \\
\hline P01009 & $46.91 / 5.37$ & 36 & $\alpha$-1-antitrypsin precursor \\
\hline P06733 & $47.38 / 6.99$ & 59 & $\begin{array}{l}\alpha \text {-enolase (EC 4.2.1.11) (2-phospho-D-glycerate hydro-lyase) } \\
\text { (Non-neural enolase) (NNE) (Enolase 1) (Phosphopyruvate hydratase) }\end{array}$ \\
\hline gil48145549 & $45.00 / 8.30$ & 33 & PGK1 \\
\hline gil67464046 & $36.51 / 8.58$ & 48 & Chain Q, crystal structure of human liver GAPDH \\
\hline gil89065310 & $29.51 / 4.93$ & 58 & $\begin{array}{l}\text { Similar to Annexin A8 (Annexin VIII) } \\
\text { (Vascular anticoagulant- } \beta \text { ) (VAC- } \beta \text { ) }\end{array}$ \\
\hline gil49456765 & $27.89 / 4.64$ & 60 & SFN \\
\hline gil90108666 & $28.08 / 5.27$ & 61 & Chain C, Crystal structure of lipid-free human apolipoprotein A-I \\
\hline gil178775 & $28.96 / 5.45$ & 56 & Proapolipoprotein \\
\hline gil442827 & $29.36 / 6.86$ & 48 & $\begin{array}{l}\text { Carbonic anhydrase II (carbonate dehydratase) (HCA II) } \\
\text { (E.C.4.2.1.1) mutant with Thr } 199 \text { replaced by Cys (T199C) }\end{array}$ \\
\hline gil55960374 & $21.26 / 7.63$ & 85 & Transgelin 2 \\
\hline gil47125412 & $15.51 / 6.6$ & 57 & Fatty acid binding protein 5 \\
\hline gil5304852 & $84.78 / 7.2$ & 34 & Aconitate hydratase \\
\hline gil51476390 & $71.39 / 5.88$ & 36 & Hypothetical protein \\
\hline gil2661039 & $36.65 / 6.53$ & 57 & $\alpha$-enolase \\
\hline gil693933 & $47.45 / 7.01$ & 48 & 2-phosphopyruvate-hydratase $\alpha$-enolase, carbonate dehydratase \\
\hline gil432376 & $33.25 / 6.0$ & 43 & Rhodanese; thiosulfate sulfurtransferase \\
\hline gil12052736 & $35.74 / 6.2$ & 55 & Hypothetical protein \\
\hline gil2781202 & $33.44 / 6.95$ & 37 & $\begin{array}{l}\text { Chain A, three-dimensional structure of } \\
\text { human electron transfer flavoprotein to } 2.1 \text { A resolution }\end{array}$ \\
\hline gil31335241 & $30.32 / 6.4$ & 52 & PNPase \\
\hline gil39645467 & $33.78 / 5.64$ & 43 & ANXA4 protein \\
\hline gil5822091 & $26.47 / 5.31$ & 30 & Chain H, cathepsin D at $\mathrm{pH} 7.5$ \\
\hline gil62897923 & $29.86 / 6.02$ & 48 & Prohibitin variant \\
\hline gil662841 & $22.44 / 7.83$ & 59 & Heat shock protein 27 \\
\hline gil5803013 & $29.05 / 6.77$ & 57 & Endoplasmic reticulum protein 29 isoform 1 precursor \\
\hline gil62087614 & $32.38 / 6.86$ & 58 & Aldo-keto reductase family 1, member $\mathrm{C} 2$ variant \\
\hline gil4758638 & $25.15 / 6.0$ & 68 & Peroxiredoxin 6 \\
\hline gil20127592 & $36.29 / 7.1$ & 35 & Aldo-keto reductase family 1 , member B10 \\
\hline gil14209610 & $14.06 / 8.04$ & 61 & Tyrosine hydroxylase \\
\hline
\end{tabular}


Table II. Proteins expressed in pre-cancerous lesions of hepatocellular cancinoma.

\begin{tabular}{|c|c|c|c|}
\hline NCBI no. & $\begin{array}{l}\text { Molecular weight } \\
\qquad\left(\mathrm{x} 10^{3} / \mathrm{IP}\right)\end{array}$ & $\begin{array}{c}\text { Sequence } \\
\text { coverage }(\%)\end{array}$ & Name \\
\hline gil52545505 & $12.48 / 8.17$ & 82 & Hypothetical protein (Homo sapiens) \\
\hline gil5031635 & $18.73 / 8.22$ & 51 & Cofilin 1 (non-muscle) \\
\hline gil57209017 & $20.91 / 9.63$ & 22 & Chromosome 9 open reading frame 3 \\
\hline gil62177133 & $32.07 / 6.06$ & 52 & MAWD binding protein isoform a \\
\hline gil16974817 & $32.88 / 8.69$ & 55 & $\begin{array}{l}\text { Chain B, X-ray crystal structure of the E170q mutant } \\
\text { of human L-3-Hydroxyacyl-Coa dehydrogenase }\end{array}$ \\
\hline gil10947139 & $34.91 / 6.72$ & 49 & Arginase, type I \\
\hline gil33357604 & $54.88 / 5.96$ & 68 & $\begin{array}{l}\text { Chain } \mathrm{H} \text {, Cys302ser mutant of human mitochondrial } \\
\text { aldehyde dehydrogenase complexed with } \mathrm{Nad}+\text { and } \mathrm{Mg} 2+\end{array}$ \\
\hline gil14043187 & $62.18 / 8.25$ & 46 & Aldehyde dehydrogenase 4 family, member A1 \\
\hline gil55957302 & $27.85 / 6.23$ & 35 & Glutathione S-transferase $\omega 1$ \\
\hline gil2914417 & $22.30 / 6.86$ & 60 & $\begin{array}{l}\text { Chain B, Tyr34->phe mutant of human mitochondrial } \\
\text { manganese superoxide dismutase }\end{array}$ \\
\hline gil2780819 & $22.30 / 6.86$ & 56 & Chain B, human manganese superoxide dismutase mutant Q143n \\
\hline gil913159 & $21.04 / 7.42$ & 65 & Neuropolypeptide h3 \\
\hline gil703083 & $16.24 / 5.0$ & 57 & Cytochrome b5 \\
\hline gil2098329 & $13.37 / 5.94$ & 62 & Human protein disulfide isomerase, $\mathrm{Nmr}, 40$ structures \\
\hline gil14150035 & $85.34 / 5.04$ & 36 & Pleckstrin and Sec7 domain containing 2 \\
\hline gil2972562 & $52.28 / 6.88$ & 64 & Collagen, type XXIII, $\alpha 1$ \\
\hline gil17974508 & $56.07 / 9.76$ & 44 & MAGED4 protein \\
\hline gil20151194 & $46.35 / 6.71$ & 39 & Chain F, structure of human glutamate dehydrogenase-Apo form \\
\hline gil219888 & $25.88 / 7.60$ & 50 & Immunoglobulin $\lambda$ light chain \\
\hline gil16974817 & $32.87 / 8.69$ & 47 & $\begin{array}{l}\text { Chain B, X-ray crystal structure of the E170q mutant } \\
\text { of human L-3-Hydroxyacyl-Coa dehydrogenase }\end{array}$ \\
\hline gil57209582 & $32.71 / 7.66$ & 46 & Protein kinase, cGMP-dependent, type I \\
\hline gil3004714 & $13.28 / 5.30$ & 79 & $\operatorname{IgM}$ heavy chain variable region \\
\hline gil21361331 & $166.08 / 6.3$ & 32 & Carbamoyl-phosphate synthetase 1 , mitochondrial \\
\hline gil21070956 & $89.96 / 5.11$ & 33 & Component of oligomeric golgi complex 4 \\
\hline gil23620474 & $55.32 / 6.29$ & 49 & Protein tyrosine phosphatase, non-receptor type substrate 1 , precursor \\
\hline gil4504919 & $53.70 / 5.52$ & 59 & Keratin 8 \\
\hline gil6137684 & $54.43 / 5.70$ & 29 & $\begin{array}{l}\text { Chain } \mathrm{H} \text {, human mitochondrial aldehyde dehydrogenase } \\
\text { complexed with } \mathrm{Nad}+\text { and } \mathrm{Mn} 2+\end{array}$ \\
\hline gil58041790 & $41.82 / 6.92$ & 48 & tRNA isopentenylpyrophosphate transferase isoform 3 \\
\hline gil4885049 & $42.36 / 5.23$ & 27 & Cardiac muscle $\alpha$ actin proprotein \\
\hline gil4501901 & $46.11 / 5.77$ & 58 & Aminoacylase 1 \\
\hline gil4456582 & $13.26 / 7.96$ & 36 & Immunoglobulin heavy chain variable region \\
\hline gil32189394 & $56.55 / 5.26$ & 68 & $\begin{array}{l}\text { ATP synthase, } \mathrm{H}+\text { transporting, } \\
\text { mitochondrial } \mathrm{F} 1 \text { complex, } \beta \text { subunit precursor }\end{array}$ \\
\hline
\end{tabular}

PMFs were used to search NCBInr and Swiss-Port databases using Mascot or ProFound software. Based on the molecular weight and isoelectric point of the 2-DE protein spots, 80 proteins were identified: 48 proteins overexpressed in HCC (Table I) and 32 proteins overexpressed in other liver lesions, excluding HCC (Table II).

Expression of HSP70 and Cathepsin D in primary hepatocellular carcinoma. Cath-D and HSP70, which were highly expressed in HCC tissue, were identified by proteomics techniques. In order to further examine the characteristics of these proteins, we confirmed the expression of Cath-D and HSP70 in HCC cells by immunohistochemistry with Cath-D and HSP70-specific antibody. The results revealed that the HSP70 was expressed at very low levels in normal liver tissue. In the adjacent non-cancerous chronic liver cirrhosis, HSP70 expression was slightly increased in the cytoplasm of some liver cells, and was increased further in altered cell lesions. HSP70 was expressed in almost all the HCC cancer cells and was located in the cytoplasm, with a brownish yellow staining color and mostly average staining intensity. At the cancer nest edge and in the tissue surrounding the junction, HSP70 was found to be significantly expressed. Cath-D was finely granular in the cytoplasm and membrane of cancer cells. Cath-D showed 


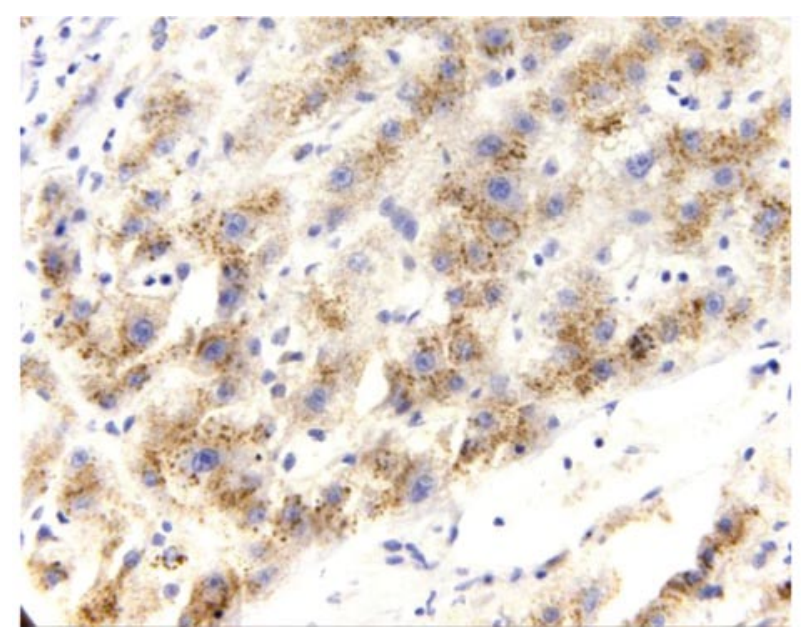

Figure 3. Immunohistochemical detection of Cath-D in pre-cancerous lesions. The distribution of Cath-D-positive granules in the cytoplasm was mostly concentrated at the edge of the nucleus away from the sinusoid or liver cell-adjacent area, or was gathered in the center of the liver board.

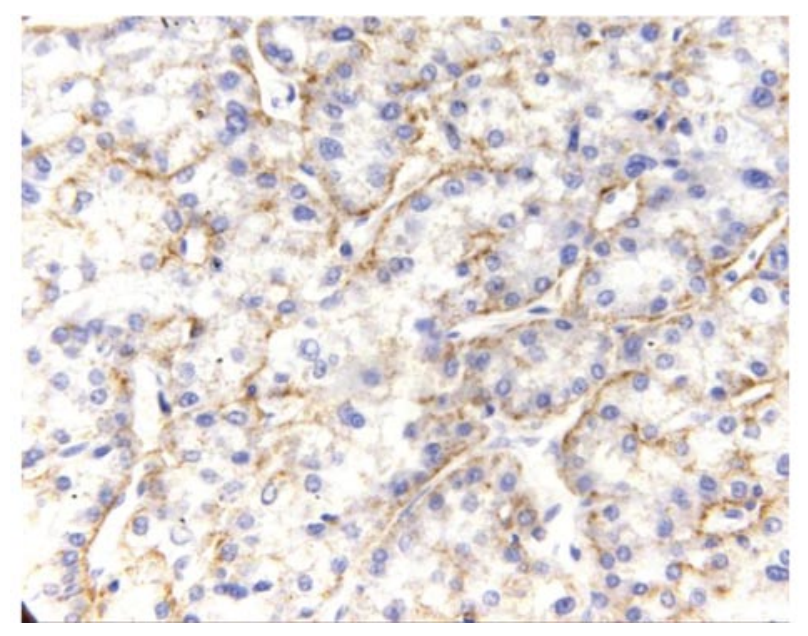

Figure 4. Immunohistochemical detection of Cath-D in HCC. Cath-Dpositive products were mainly located in the membrane of cancer cells.

diffuse weak positive expression in large-cell lesions of the liver tissues, whereas in small-cell lesions, the positive cells were located at the edge of lesions. The distribution of positive granules in the cytoplasm was mostly concentrated at the edge of the nucleus away from the sinusoid or the liver cell-adjacent area, or gathered in the center of the liver board (Fig. 3). In HCC, Cath-D-positive products were mainly located in the membrane of cancer cells or cytoplasma near the membrane as brown granules, and had a significantly increased staining intensity (Fig. 4).

\section{Discussion}

HCC is one of the most common malignant tumors. Due to its late diagnosis and the lack of effective conventional treatments, the mortality rate for HCC is very high $(6,7)$. When diagnosed during the early stages, $\mathrm{HCC}$ has a 5-year survival rate due to the availability of more effective treatments and the better bodily function of the patients. Early diagnosis is therefore crucial for the successful treatment of $\mathrm{HCC}$, and the identification of a highly-sensitive and selective biological marker is essential for early diagnosis.

In the past, proteomics analysis of HCC mostly used liver cancer cell lines or tumor tissue extracts to analyze changes in the protein expression profile $(8,9)$. Due to the complexity and heterogeneity of tumor tissue, it is impossible to collect the same types of cell groups; rather a mixture of many cell components is obtained. Although tumor cells in vitro are very similar to tumor cells in the complex environment of the body, they demonstrate a variety of features, which differ in some respects. In this study, the specific cells directly obtained from the tissue of pre-cancerous lesions and HCC by microdissection greatly enhanced the homogeneity of tumor cells. Comparative analysis of the protein expression profiles of HCC and precancerous lesions revealed that the differentially expressed proteins were respectively involved in cell growth, differentiation and proliferation, protein synthesis and metabolism, and signal transduction. Examination of these proteins may aid in the identification of the protein molecular markers for the early diagnosis of HCC and contribute to the understanding of the molecular mechanisms of hepatocarcinogenesis.

What follows is a discussion of the function of the differentially expressed proteins identified in the present study, and their relation to the development of $\mathrm{HCC}$.

Transgelin 2 and Stratifin. Transgelin 2 and Stratifin may be specific diagnostic markers of hepatocellular carcinoma. Transgelin 2 was highly expressed in HCC, but was not detected in the pre-cancerous lesions. To our knowledge, the overexpression of Transgelin in HCC has not been previously reported. Transgelin, also known as SM22- $\alpha$, of the calciumbinding protein family, is an actin-binding protein with a molecular weight of $22 \mathrm{kDa}$. Transgelin was overexpressed in gastric cancer and renal cell carcinoma, and was capable of inducing IgG responses in vivo in some patients (10-12). In order to identify a potential diagnostic marker for liver cancer and immunotherapy molecular targets, Shi et al (13) detected tumor antigens and tumor-associated antigens in patients with HCC by serological analysis of cDNA expression libraries (SEREX). In 30 antigens reacted with serum IgG from HCC patients, the mRNA expression patterns of 14 tumor samples were altered, 9 of which were up-regulated and 5 down-regulated. Transgelin 2 mRNA showed high expression in $69 \%$ of the liver samples (13). In the present study, Transgelin 2 protein was detected in HCC tissues, suggesting that it may be a diagnostic marker of HCC.

Stratifin (SFN; 14-3-3б) protein is a member of the 14-3-3 superfamily. SFN can be combined with a variety of proteins, including signal protein kinase, phosphorylase and transmembrane receptors, and plays an important role in the regulation of the cell cycle and cell apoptosis (14). In recent years, the function of SFN (14-3-3б) in tumors has been reported, but with varying results in different epithelial tumors. As a major G2/M checkpoint controlling gene, 14-3-3 $\sigma$ is inactive in a variety of cancers, due mostly to hypermethylation $(15,16)$. In cervical dysplasia and squamous cell carcinoma, 14-3-3 $\sigma$ showed diffuse strong positive expression, related to immune activity (17). SFN was expressed in $97 \%$ of intestinal metaplasia, $100 \%$ of gastric epithelial dysplasia, 
and only $3 \%$ of normal gastric mucosa samples. Positive expression of 14-3-3 $\sigma$ was also observed in $92 \%$ of primary gastric cancers, suggesting that it is very useful for the early diagnosis of human gastric cancer and for targeted therapy of gastric pre-cancerous lesions (18). In the present study, high expression of 14-3-3 $\sigma$ protein was detected in HCC tissues, but was not found in the corresponding adjacent non-cancerous tissues, further indicating that the overexpression of 14-3-30 protein may be related to the development of liver cancer (19).

Mitochondrial manganese superoxide dismutase. The expression of mitochondrial manganese superoxide dismutase (Mn-SOD) is down-regulated in human hepatocellular carcinoma. Mn-SOD expression was lower in human HCC tissues than in chronic hepatitis and cirrhosis. It can be speculated that a variety of cytokines are secreted by infiltrating inflammatory cells and inflammatory chemokines in the tumor microenvironment, which induces an increase in Mn-SOD expression. Mn-SOD protects cells from oxidative stress and maintains the normal function of cells. When liver cells were transformed into cancer cells, the amount of Mn-SOD in these cells was reduced. This decrease was associated with a decrease in the mature form of the MnSOD transcript, in part accompanied by an increase of the processed form of MnSOD transcript. Therefore, the level of Mn-SOD mRNA transcription or translation processing may determine the level of Mn-SOD expression of human tumor cells (20). The reduced expression of $\mathrm{Mn}-\mathrm{SOD}$ in tumor cells may be related to carcinogenesis and the development of HCC.

Heat shock protein 70 family. The expression of heat shock protein 70 (HSP70) is up-regulated in human hepatocellular carcinoma. The HSP70 family has three members, including heat shock $70 \mathrm{kDa}$ protein $9 \mathrm{~B}$ and its precursors, heat shock $70 \mathrm{kDa}$ protein 5 and glucose-regulated protein (GRP78). These were increasingly expressed in human HCC. The pathogenesis of HCC is a complex and multistage process, with the majority of cases involving liver cirrhosis caused by chronic HBV and HCV persistent infections (21). The development of HCC is associated with chronic liver disease and generally evolves from pre-cancerous lesions and early-stage cancer to a progressed morphology. Chuma et al (22) compared the expression profiles of early and progressed HCCs and their corresponding non-cancerous liver tissues with an oligonucleotide array. The results showed that HSP70 was the most up-regulated gene in early HCC. Further examination using immunohistochemistry and RT-PCR confirmed this finding. The level of expression of HSP70 in progressed HCC was significantly higher than that in early HCC. The expression of HSP70 in early HCC was higher than in pre-cancerous lesions (22). The expression of HSP70 has been found to gradually increase with the development of liver cancer. The immunohistochemical results of the present study support this finding, suggesting that HSP70 may be a sensitive marker in the differential diagnosis of early liver cancer and pre-cancerous lesions compared to non-cancerous liver tissue.

Cathepsin-D. Cath-D may play different roles in the process of hepatocarcinogenesis. In the present study, we verified the up-regulation of the proteins HSP70 and Cath-D in 28 cases of liver cancer and cirrhosis using immunohistochemistry. The results showed that Cath-D is not only expressed in cancer tissue, but also in liver cirrhosis adjacent to cancer, nodules of altered hepatocytes and normal liver tissues. However, the position of Cath-D in cells is different in different tissues, suggesting that the function of Cath-D may be changed in HCC carcinogenesis.

Maguchi purified an apparently homogeneous form of Cath-D from normal human liver and hepatocellular cancer in 1988, and found that the origin of purified Cath-D could not be distinguished from normal liver or liver cancer in terms of specific activity, antigenicity, subunit and amino acid composition or trypsin peptides (23). However, the purified enzyme from liver cancer showed greater heterogeneity of the charge, which produced a variety of acidic variants, whereas in the normal liver the enzyme was deficient or present in very low amounts. The amount of Cath-D mannose-6-phosphate in liver cancer was twice that of the normal liver. Therefore, the heterogeneity of Cath-D in tumor tissue may be related to the carcinogenesis of liver cancer.

This study also detected other protein molecules related to the development of liver cancer, such as prohibitin PHB, DJ-1, $\alpha$-enolase, PDX6, aldehyde-ketone reductase B10, PGK1 and $\alpha 1-\mathrm{AT}$. Although their role and function in the development of HCC is not entirely clear, they are expected to become candidate markers for future study of the mechanisms of liver cancer.

\section{Acknowledgements}

This study was supported by a grant from the National Nature Science Foundation of China (No. 30782403) and the Development Program of Science and Technology of Shaanxi Province (No. 2008K09-05). The authors thank Baochang Lai for technological advice.

\section{References}

1. Stefaniuk P, Cianciara J and Wiercinska-Drapalo A: Present and future possibilities for early diagnosis of hepatocellular carcinoma. World J Gastroenterol 16: 418-424, 2010.

2. $\mathrm{Su} \mathrm{Q}$, Benner A, Hofmann WJ, Otto G, Pichlmayr R and Bannasch P: Human hepatic preneoplasia: phenotypes and proliferation kinetics of foci and nodules of altered hepatocytes and their relationship to liver cell dysplasia. Virchows Arch 431: 391-406, 1997.

3. Su Q, Zhang SX, Yang SJ, Liu J and Liu YF: Precancerous changes in hepatitis B and liver cirrhosis: a morphological and immunohistochemical study. J Fourth Milit Med Univ 16: 85-88, 1995.

4. Su Q: Precancerous lesion of human hepatocellular carcinoma. Chinese Journal of Diagnostic Pathology 10: 112-115, 2003.

5. Zhou L, Yang XF, Wang Y, Zhang YT, Geng YP, Si LS and Wang YL: Identification of metastasis-associated proteins of ovarian cancer by proteomics. Zhonghua Bing Li Xue Za Zhi 36: 814-818, 2007.

6. Bosch FX, Ribes J, Cléries R and Díaz M: Epidemiology of hepatocellular carcinoma. Clin Liver Dis 9: 191-211, 2005.

7. Parkin DM, Bray F, Ferlay J and Pisani P: Global cancer statistics, 2002. CA Cancer J Clin 55: 74-108, 2005.

8. Fujii K, Kondo T, Yokoo H, Yamada T, Iwatsuki K and Hirohashi S: Proteomic study of human hepatocellular carcinoma using two-dimensional difference gel electrophoresis with saturation cysteine dye. Proteomics 5: 1411-1422, 2005.

9. Cui JF, Liu YK, Pan BS, Song HY, Zhang Y, Sun RX, Chen J, Feng JT, Tang ZY, Yu YL, Shen HL and Yang PY: Differential proteomic analysis of human hepatocellular carcinoma cell line metastasis-associated proteins. J Cancer Res Clin Oncol 130: 615-622, 2004 
10. Klade CS, Voss T and Krystek E: Identification of tumor antigens in renal cell carcinoma by serological proteome analysis. Proteomics 1: 890-898, 2001.

11. Li LS, Kim H, Rhee H, Kim SH, Shin DH, Chung KY, Park KS, Paik YK, Chang J and Kim H: Proteomic analysis distinguishes basaloid carcinoma as a distinct subtype of nonsmall cell lung carcinoma. Proteomics 4: 3394-3400, 2004.

12. Ryu JW, Kim HJ, Lee YS, Myong NH, Hwang CH, Lee GS and Yom HC: The proteomics approach to find biomarkers in gastric cancer. J Korean Med Sci 18: 505-509, 2003.

13. Shi YY, Wang HC, Yin YH, Sun WS, Li Y, Zhang CQ, Wang Y, Wang $S$ and Chen WF: Identification and analysis of tumorassociated antigens in hepatocellular carcinoma. Br J Cancer 92: 929-934, 2005

14. Lewis AG, Flanagan J, Marsh A, MP J and Mann G: Mutation analysis of FANCD2, BRIP1/BACH1, LMO4 and SFN in familial breast cancer. Breast Cancer Res 7: R1005-R1016, 2005.

15. Urano $T$, Takahashi S, Suzuki T, Fujimura $T$, Fujita $M$, Kumagai J, Horie-Inoue K, Sasano H, Kitamura T, Ouchi Y and Inoue S: 14-3-3 sigma is down-regulated in human prostate cancer. Biochem Biophys Res Commun 319: 795-800, 2004.

16. Cheng L, Pan CX, Zhang JT, Zhang S, Kinch MS, Li L, Baldridge LA, Wade C, Hu Z, Koch MO, Ulbright TM and Eble JN: Loss of 14-3-3 sigma in prostate cancer and its precursors. Clin Cancer Res 10: 3064-3068, 2004.

17. Sano T, Shimooka H, Weixa P, Segawa A, Jian Z, Motegi A Nakayama H, Oyama T and Nakajima T: Immunohistochemical expression of 14-3-3 sigma protein in various histological subtypes of uterine cervical cancers. Pathol Int 54: 743-750, 2004.
18. Cunningham SC, Kamangar F, Kim MP, Hammoud S, Haque $R$ and Iacobuzio-Donahue CA: Claudin-4, mitogenactivated protein kinase kinase 4 , and stratifin are markers of gastric adenocarcinoma precursor lesions. Cancer Epidemiol Biomarkers Prev 15: 281-287, 2006.

19. Lee IN, Chen $\mathrm{CH}$, Sheu JC, Lee HS, Huang GT, Yu CY, $\mathrm{Lu} \mathrm{FJ}$ and Chow LP: Identification of human hepatocellular carcinoma-related biomarkers by two-dimensional difference gel electrophoresis and mass spectrometry. J Proteome Res 4: 2062-2069, 2005.

20. St Clair DK and Oberley LW: Manganese superoxide dismutase expression in human cancer cells: a possible role of mRNA processing. Free Radic Res Commun 12-13 Pt 2: 771-778, 1991.

21. Kuang SY, Jackson PE, Wang JB, Lu PX, Muñoz A, Qian GS, Kensler TW and Groopman JD: Specific mutations of hepatitis B virus in plasma predict liver cancer development. PNAS 101: 3575-3580, 2004.

22. Chuma M, Sakamoto M, Yamazaki K, Ohta T, Ohki M, Asaka M and Hirohashi S: Expression profiling in multistage hepatocarcinogenesis: identification of HSP70 as a molecular marker of early hepatocellular carcinoma. Hepatology 37: 198-207, 2003.

23. Maguchi S: Tumor-associated impairment of the processing of hepatoma cathepsin D. Hokkaido Igaku Zasshi 63: 23-35, 1988. 